\title{
CYSTIC TUBERCULOSIS OF BONE IN CHILDREN
}

\author{
M. N. RASOOL, S. GOVENDER, K. S. NAIDOO
}

From the University of Natal, South Africa

We treated 13 children with histologically confirmed cystic tuberculosis of bone. Ten had solitary cystic lesions and three had the multicystic form. Signs and symptoms were related mainly to the joint adjacent to the cyst.

Most lesions were in the metaphyses of long bones. They were radiolucent, round or oval, and resembled pyogenic infections, aneurysmal and simple bone cysts, cartilaginous tumours or osteoid osteoma. Only two of the children had pulmonary tuberculosis. The Mantoux skin test was negative in four children and the ESR was normal in five.

Curettage followed by anti-tuberculosis therapy for one year resulted in good healing, but two children had residual joint contractures. Biopsy should be taken from the cystic area rather than from the synovium when a joint is involved.

J Bone Joint Surg [Br] 1994; 76-B:113-7.

Received 1 June 1993; Accepted 15 July 1993

Solitary cystic tuberculosis of bone in children is uncommon: only a few cases have been described recently (HartofilakidisGarofalidis 1969; Versveld and Solomon 1982; Abdelwahab et al 1988; Nielsen, Helmig and de Carvalho 1989). The more common multiple cystic form was first described in 1920 as 'Jüngling's disease' or 'osteitis tuberculosa multiplex cystoides' (Komins 1952; Edeikin et al 1963; O'Connor, Steel and Sanders 1970). Confusion in the terminology (Ellis 1940; Komins 1952; Girdwood 1953; Edeikin et al 1963; Echeverria and Kaude 1978) arose because Jüngling's description was that of sarcoidosis which he considered to be a manifestation of tuberculosis.

In 1952, Komins proposed that the bone lesions of sarcoidosis be renamed 'osteitis multiplex cystoides sarcoidosa' and the characteristic multiple 'cystic' bone lesions of

M. N. Rasool, FCS, Senior Consultant

S. Govender, FRCS Ed, Senior Surgeon/Senior Lecturer

K. S. Naidoo, FRCS Ed, Professor and Head

Department of Orthopaedics, University of Natal, PO Box 17039, Congella 4013, Durban, Republic of South Africa.

Correspondence should be sent to Mr M. N. Rasool.

(C)1994 British Editorial Society of Bone and Joint Surgery $0301-620 X / 94 / 1717 \$ 2.00$ juvenile cases of tuberculosis be termed multiple pseudocystic tuberculosis. He emphasised the fact that these lesions were not true cysts.

Typically, the bone lesions in tuberculosis are radiolucent, round to oval, and are situated in the peripheral skeleton near the metaphysis. The cyst-like appearance is due to the variable marginal sclerosis. These 'cysts', however, can occur anywhere in the skeleton. Solitary lesions may mimic bacterial and fungal infections, simple or aneurysmal bone cysts, cartilaginous tumours and osteoid osteoma (O'Connor et al 1970; Goldblatt and Cremin 1978; Benkeddache and Gottesman 1982; Abdelwahab et al 1988, 1989; Shannon et al 1990).

\section{PATIENTS AND METHODS}

From 1984 to 1991 we treated 13 children, 8 boys and 5 girls, with a mean age of 5 years (1 to 12). The duration of symptoms ranged from 1 week to 3 months. Table I gives the clinical details. Five children had a history of mild trauma. The symptoms and signs, which included pain and swelling, were related mainly to the joint adjacent to the bone involved. There was a limp when the lower limb was involved. Three children were diagnosed as having pyogenic osteomyelitis and underwent surgical drainage shortly after admission. The diagnosis of tuberculosis was made subsequently.

A discharging sinus over the greater trochanter was seen in one child and another had dactylitis of the thumb and middle finger. Other sites involved were the spine and mandible. Two children had a gibbus without neurological signs and one had a swelling over the angle of the mandible.

Loss of weight and appetite, fever and cough were not predominant features. Chest involvement was seen in two children.

The ESR, full blood count and the Mantoux skin test were done in all patients, as were chest radiographs and bone scans.

The ESR ranged from $46 \mathrm{~mm} / \mathrm{hr}$ to $95 \mathrm{~mm} / \mathrm{hr}$ in eight children; in five it was normal. The haemoglobin level ranged from $8.5 \mathrm{~g} \%$ to $12.6 \mathrm{~g} \%$ and the white cell count from $5.6 \times 10^{9} / 1$ to $13.8 \times 10^{9} /$. The Mantoux test was positive in nine children and negative in four. A normal ESR and negative Mantoux test were seen in four.

Radiological findings. Ten of the children had solitary cystic lesions, and three had more than one (Table I). The total number of lesions was 17 . There were nine in the 
metaphyses of long bones, three in the epiphyses and one in the diaphysis. The other lesions were in the hand (2) and pelvis (2). The cysts were between $0.5 \mathrm{~cm}$ and $3 \mathrm{~cm}$ in diameter. There was localised osteoporosis in all cases. Sequestrum formation was seen in only one case (case 4); the dense sclerosis around this sequestrum resembled the appearance of an osteoid osteoma.

Metaphyseal lesions. These were typically expanding, radiolucent and round to oval with a variable amount of sclerosis. There was a multilocular appearance in two cases. Mild periosteal reaction occurred in five cases and a dense periosteal reaction around the distal humerus in one (case 5 , Fig. 1). Lesions in the distal tibia and proximal humerus were similar to aneurysmal and simple bone cysts (cases 1 and 3, Fig. 2). In two cases the growth plate was transgressed and the lesions involved the epiphyses (cases 5 and 9). In the latter the appearance resembled a chondroblastoma (Fig. 3).

Epiphyseal lesions. Primary epiphyseal involvement was seen in only two cases as small punched-out areas with marginal sclerosis.

Diaphyseal lesion. The proximal half of the radius was involved in case 6 with multicystic lesions.

Hand. In case 8, the thumb metacarpal and the proximal phalanx of the middle finger showed multilocular lesions with the typical honeycomb appearance (Fig. 4).

Pelvis. In case 13 the body of the pubis was involved and in case 12 the region of the acetabulum showed a multilocular appearance with joint widening.

Joint involvement. In addition to the hip in case 12, the adjacent joint was involved in all patients with epiphyseal or metaphyseal lesions except case 11 . All showed soft-tissue swelling, osteoporosis and joint-space widening.

Other sites. In two children radiography showed pulmonary involvement, and two had vertebral lesions with the destruction of adjacent bodies producing a mild gibbus. One child had destructive changes in the mandible.

Treatment. In all patients the diagnosis of tuberculosis was confirmed histologically. In the ten solitary cystic lesions the biopsy was from the involved site. In two of the three multifocal cases (cases 6 and 8) the diagnosis was accepted from histological reports of spinal biopsies. In the third (case 5), with multicystic changes, the diagnosis was by biopsy of the distal humerus only. Care was taken to obtain biopsy specimens from the area of bone destruction rather than from the synovium of the adjacent joint.

In each case, the cyst-like cavity was curetted to remove all granulation tissue and pus, but bone grafting was not used to fill the resultant defect. After surgery, the affected limb was splinted in plaster for four weeks, using a bilateral above-knee abduction plaster for the patient with hip involvement. Active physiotherapy started after the removal of the splint. Anti-tuberculosis treatment with isoniazid and pyrazinamide was given for 12 months, and rifampicin was used for six months.

\section{RESULTS}

Follow-up was from 6 months to 8 years (mean 3 years) in 12 children. One child (case 10) was lost to follow-up after three months. All patients (except cases 2 and 12) had a full

Table I. Details of 13 children with cystic tuberculosis of bone

\begin{tabular}{|c|c|c|c|c|c|c|c|}
\hline Case & $\begin{array}{l}\text { Age } \\
(\mathbf{y r})\end{array}$ & Sex & Anatomical site & Radiological features & $\begin{array}{l}\text { Follow-up } \\
(\mathbf{y r})\end{array}$ & Healing & Joint movement \\
\hline 1 & 1 & $\mathbf{F}$ & Proximal humeral metaphysis & Unilocular, round & 0.5 & Sclerosis & Full $\mathrm{ROM}^{*}$ \\
\hline 2 & 1 & $\mathbf{F}$ & Proximal ulnar metaphysis & Unilocular, round & 2 & Complete & FFD $+20^{\circ}$ elbow \\
\hline 3 & 1.5 & $\mathbf{M}$ & Distal tibial metaphysis & Multilocular, oval & 3 & Complete & Full ROM \\
\hline 4 & 2 & $\mathbf{M}$ & Neck of femur & Unilocular, oval, sequestrum & 3 & Sclerosis & Full ROM \\
\hline 5 & 2 & $\mathbf{F}$ & $\begin{array}{l}\text { Distal humeral metaphysis } \\
\text { Distal humeral metaphysis } \\
\text { Proximal tibial metaphysis }\end{array}$ & $\begin{array}{l}\text { Multilocular, oval, dense periostitis } \\
\text { Unilocular, oval } \\
\text { Unilocular, round }\end{array}$ & 3 & $\left.\begin{array}{l}\text { Small distal humerus } \\
\text { Complete } \\
\text { Complete }\end{array}\right\}$ & Full ROM \\
\hline 6 & 3 & $\mathbf{M}$ & $\begin{array}{l}\text { Distal humeral metaphysis } \\
\text { Proximal radial diaphysis }\end{array}$ & $\begin{array}{l}\text { Unilocular, oval } \\
\text { Unilocular, round }\end{array}$ & 3 & $\begin{array}{l}\text { Complete } \\
\text { Complete }\end{array}$ & Full ROM \\
\hline 7 & 3 & $\mathbf{M}$ & Distal femoral epiphysis & Punched out, round & 4 & Complete & Full ROM \\
\hline 8 & 5 & $\mathbf{M}$ & $\begin{array}{l}\text { Thumb metacarpal } \\
\text { Proximal phalanx middle finger }\end{array}$ & $\begin{array}{l}\text { Honeycombed, round } \\
\text { Honeycombed, round }\end{array}$ & 8 & $\begin{array}{l}\text { Short metacarpal } \\
\text { Complete }\end{array}$ & Full hand function \\
\hline 9 & 7 & $\mathbf{M}$ & Distal tibial metaphysis & Unilocular, oval & 2 & Complete & Full ROM \\
\hline 10 & 8 & $\mathrm{~F}$ & Distal radial epiphysis & Punched out, round & 0 & Lost to follow-up & - \\
\hline 11 & 9 & $\mathbf{F}$ & Greater trochanter & Unilocular, oval & 1 & Sclerosis & Full ROM \\
\hline 12 & 11 & $\mathbf{M}$ & Acetabulum & Multilocular, oval & 1.5 & Complete & Ankylosed hip FFD $30^{\circ}$ \\
\hline 13 & 12 & $\mathbf{M}$ & Body of pubis & Unilocular, round & 2 & Sclerosis & Full ROM \\
\hline
\end{tabular}

* range of movement

$\dagger$ fixed flexion deformity 

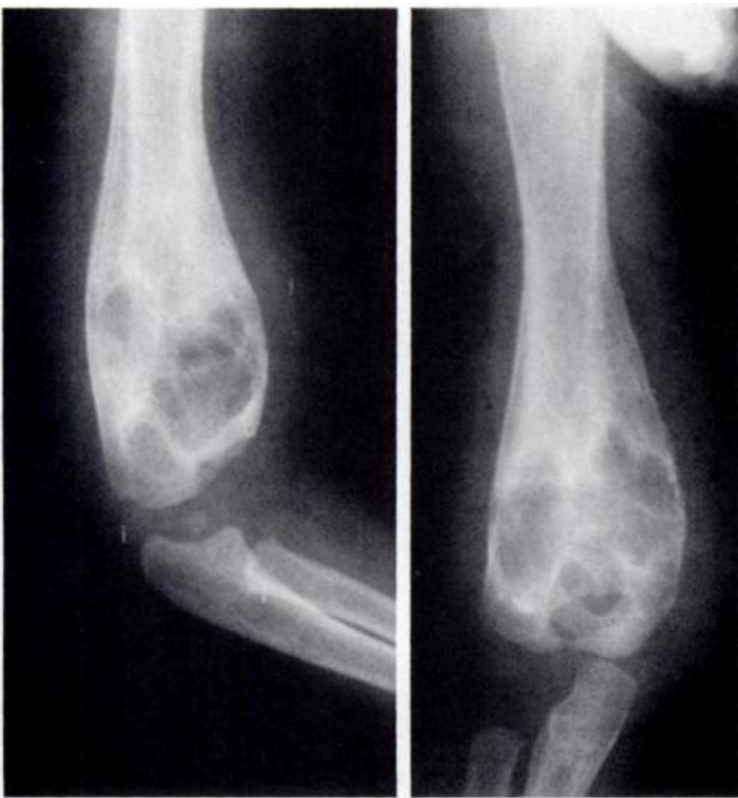

Fig. 1a
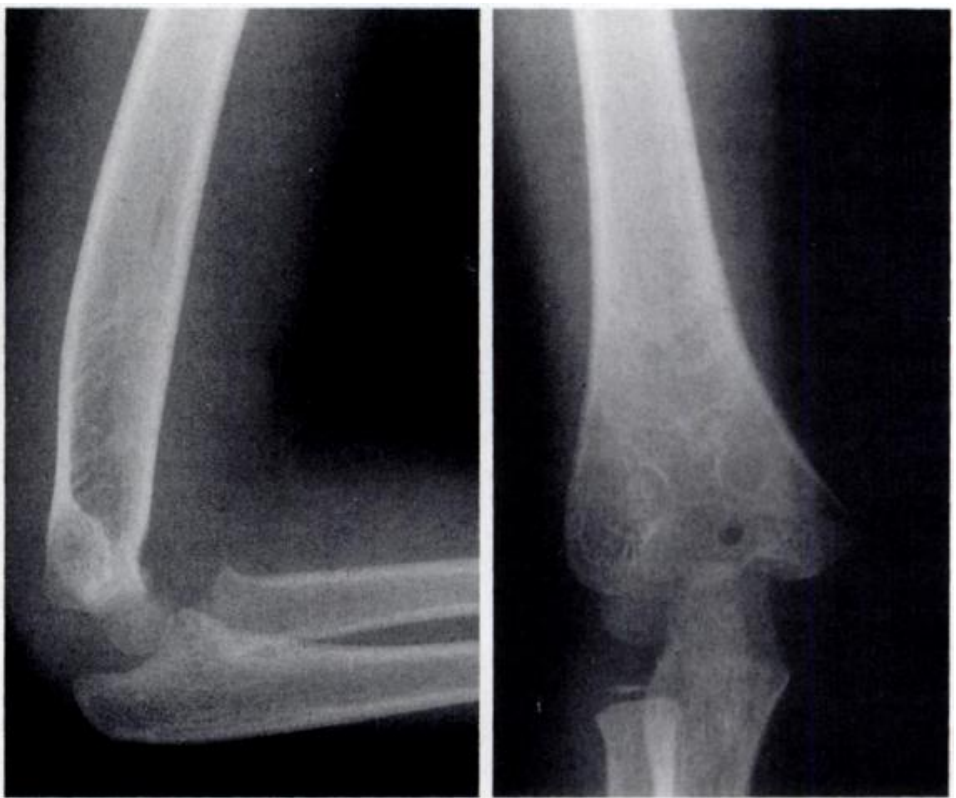

Fig. 1b

Figure 1a - A multilocular cyst in the distal humerus of a one-year-old child. There is a dense periosteal reaction. Figure $1 \mathrm{~b}-\mathrm{After}$ three years, there is excellent remodelling. There was full elbow movement.
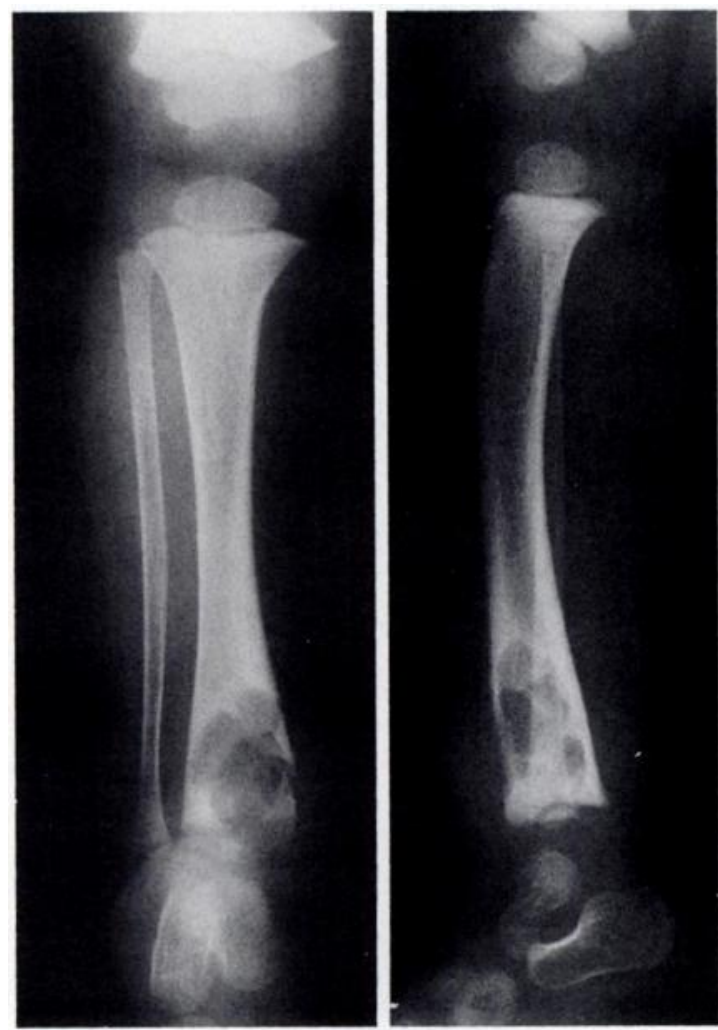

Fig. 2a

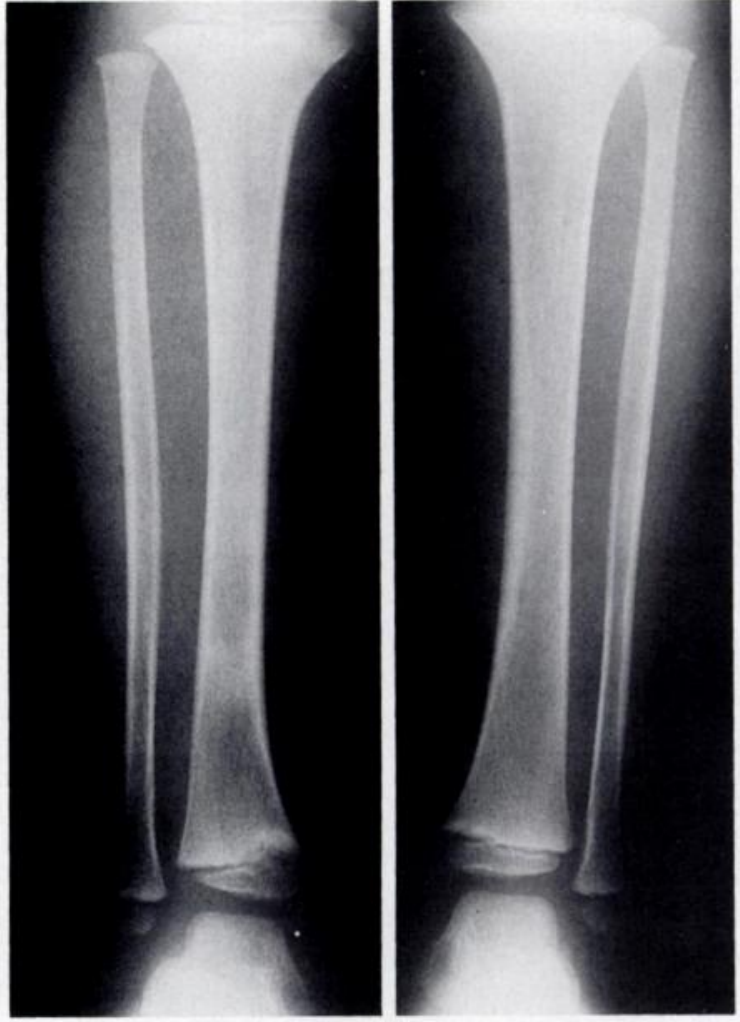

Fig. $2 b$

Figure $2 a-A$ multilocular cyst in the distal tibia of a one-year-old child. Figure $2 b-$ After three years there is good healing. The normal leg is shown for comparison. 

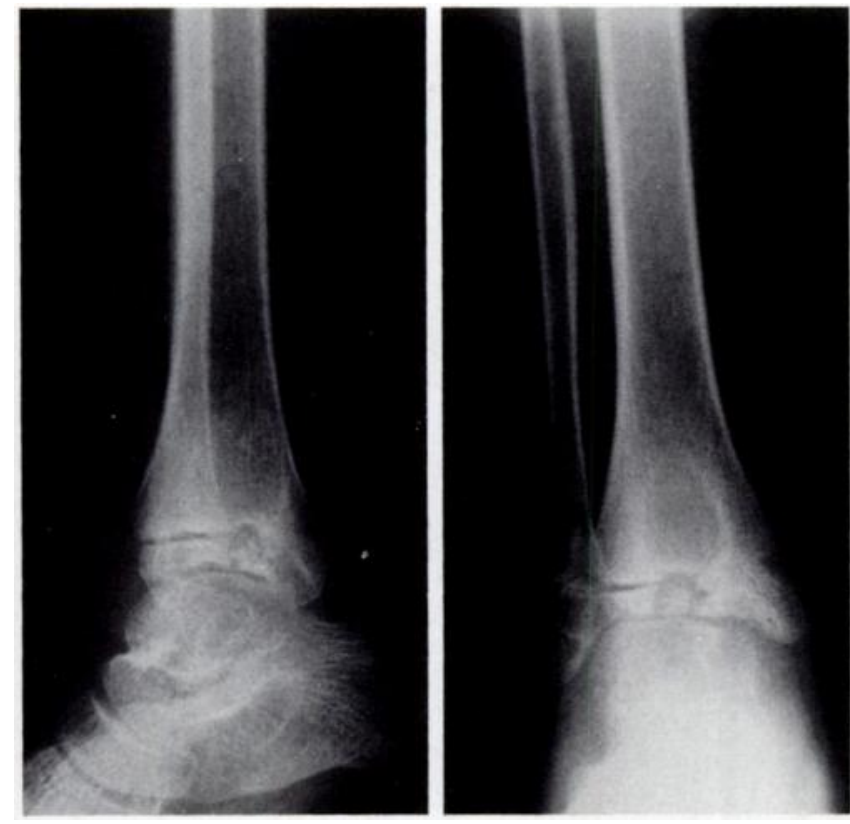

Fig. 3a
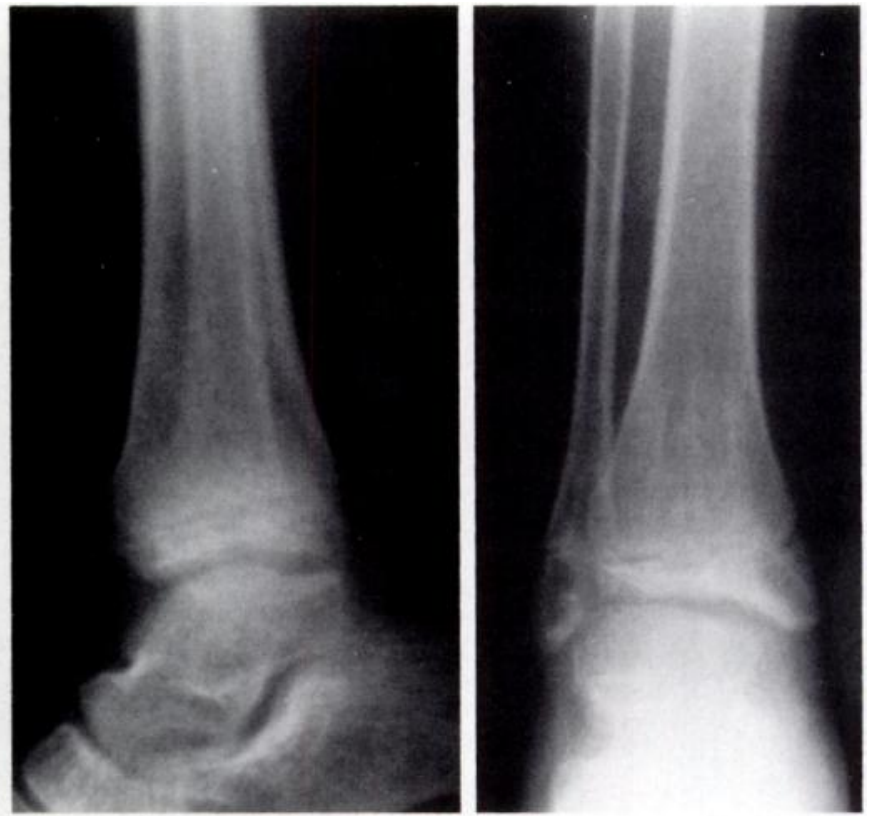

Fig. 3b

Figure $3 a-A$ cystic lesion extending into the epiphysis of the distal tibia in a five-year-old child. Figure $3 b-$ After two years there is healing with residual sclerosis.

range of painless movement of the adjacent joints at the end of medical treatment.

Case 2 had a residual $20^{\circ}$ flexion contracture of the elbow, with full flexion but limited forearm rotation.

Case 12, the child with acetabular involvement, had a painless fibrous ankylosis of the hip with a mild flexion deformity. In these two patients the radiological defects had healed well. In the remaining 11 patients (13 sites) the radiological defects healed completely at eight sites and in the other five there was healing with some sclerosis. There was evidence of growth disturbance in two patients, with underdevelopment of the humeral condyle in case 5 (Fig. 1b) and of the thumb metacarpal in case 8 (Fig. 4b). Remodelling of expanded lesions occurred in all the patients.

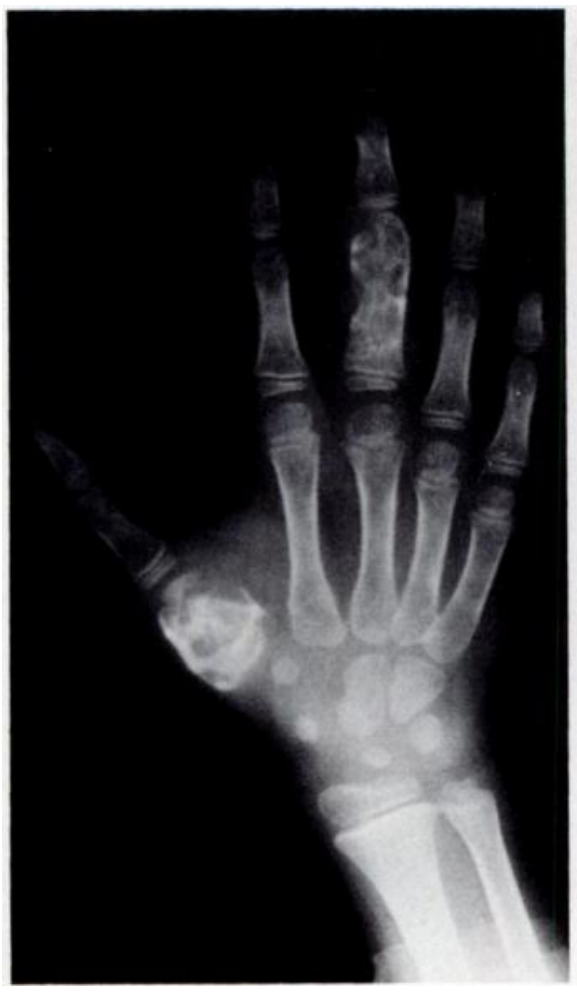

Fig. 4a

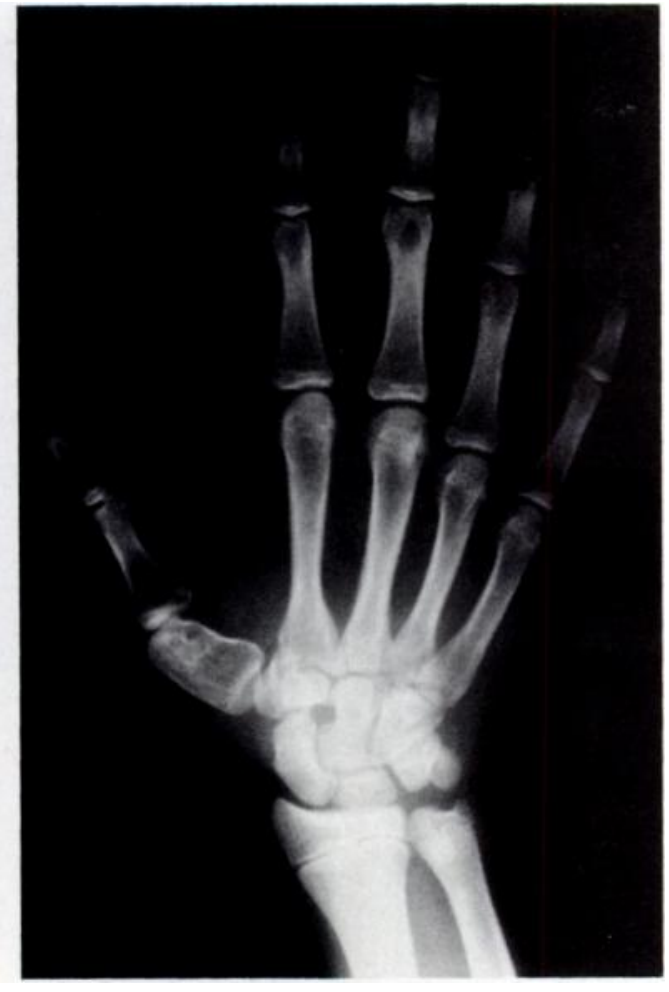

Fig. 4b
Figure $4 a-$ Cystic tuberculosis of the hand in a four-year-old child showing a honeycomb appearance in the thumb metacarpal and the proximal phalanx of the middle finger. Figure $4 \mathrm{~b}-$ Eight years later the lesions are well healed. The thumb metacarpal is underdeveloped. 


\section{DISCUSSION}

Tuberculosis remains a major cause of skeletal infection in many parts of the world. In about $50 \%$ of patients the vertebrae are the site of skeletal involvement (Poppel et al 1953; Abdelwahab et al 1988). Although multifocal cystic tuberculosis of bone is well known, solitary cystic lesions are uncommon and less well documented in the recent literature (Kumar and Saxena 1988).

In adults the common sites are the skull and axial skeleton and the shoulder and pelvic girdles (Komins 1952; O'Connor et al 1970). In children, the metaphyses of the long bones are often the sites of infection. This predilection is probably due to the vascular structure of the long bones in this region (Edeikin et al 1963). Tubercle bacilli probably lodge in the small terminal branches of the arteries of the metaphysis and grow, caseate and produce a cystic lesion.

Bone lesions appear on radiographs as round or oval, occasionally multilocular areas of radiolucency, usually expanding with mild periosteal reaction. They may extend to involve the cortex and may break through it. The physis is no barrier to spread: lesions may extend into the epiphysis. Sequestra are uncommon and smaller than in pyogenic infection (Komins 1952; Goldblatt and Cremin 1978; Abdelwahab et al 1988). Cystic tuberculosis of the short tubular bones of the hands and feet in young children is uncommon (Westman, Barson and Powell 1984; Abdelwahab et al 1989), usually showing osteoporosis and honeycombing with or without sequestrum formation. Cystic expansion of bone, termed 'spina ventosa', may occur (Benkeddache and Gottesman 1982; Abdelwahab et al 1989).

Kumar and Saxena (1988) considered that the bone lesions were usually solitary because sensitisation of the patient to the tubercle bacillus occurred before the onset of skeletal disease. However, if host immunity is poor and the immune response has been altered, the lesions may multiply. Since tubercle bacilli are blood-borne, individual lesions start at different sites and multifocal lesions may be at different stages of development.

It has been stated that tuberculosis of bone is almost always secondary to a primary focus, usually in the chest (Edeikin et al 1963), and that the tuberculin reaction is always positive (Benkeddache and Gottesman 1982). Our study showed chest involvement in only two patients and four of our patients had a negative Mantoux skin test even after repeated skin testing. The ESR was normal in four patients. Similar negative findings regarding the ESR and Mantoux test have already been reported (Nielsen et al 1989). Goldblatt and Cremin (1978) found that only $31 \%$ of patients had radiological involvement of the chest in their series of osteoarticular tuberculosis.

Versveld and Solomon (1982) suggested that in cystic tuberculosis near a joint, the cyst-like changes in bone reflect the major granulomatous lesion; biopsy from this area will allow a more specific diagnosis of tuberculosis. We found that biopsy of synovium alone may be inconclusive and may be reported as showing non-specific changes.
After curettage, bone defects usually fill adequately and we found that bone grafting as suggested by Kumar and Saxena (1988) was not necessary. Resolution and bone remodelling of expanded or multilocular lesions were satisfactory in our experience as reported by Versveld and Solomon (1982). The response to modern anti-tuberculous drugs is usually dramatic: significant radiological improvement may occur as early as six weeks.

There seems to be a changing pattern of cyst-like lesions in osseous tuberculosis. Multicystic and multifocal lesions were more common 50 years ago, but it seems that solitary lesions are now predominant. This may be related to immunological factors; none of the three children in our series with multicystic tuberculosis had general dissemination of the disease. A low ESR and negative Mantoux test do not exclude tuberculosis; lesions may be asymptomatic and may only be revealed after minor trauma. Sinus formation is rare (Versveld and Solomon 1982).

Lack of familiarity with and awareness of cystic tuberculosis may lead to delay in diagnosis. Bone lesions may present in a bizarre fashion and mimic other diagnoses. Biopsy is always necessary.

No benefits in any form have been received or will be received from a commercial party related directly or indirectly to the subject of this article.

\section{REFERENCES}

Abdelwahab IF, Present DA, Gould E, Klein MJ, Nelson J. Tuberculosis of the distal metaphysis of the femur. Skeletal Radiol 1988; 17:199202.

Abdelwahab IF, Lewis MM, Klein MJ, Hermann G. Tuberculous dactylitis (right great toe). Skeletal Radiol 1989; 18:133-5.

Benkeddache Y, Gottesman H. Skeletal tuberculosis of the wrist and hand: a study of 27 cases. J Hand Surg [Am] 1982; 7:593-600.

Echeverria J, Kaude JV. Multifocal tuberculous osteomyelitis. Pediatr Radiol 1978; 7:238-40.

Edeiken J, De Palma AF, Moskowitz H, Smythe V. 'Cystic' tuberculosis of bone. Clin Orthop 1963; 28:163-8.

Ellis FA. Jungling's 'osteitis tuberculosa multiplex cystoides' is not cystic tuberculous osteitis. Acta Med Scand 1940; 104:221-4.

Girdwood W. Multiple cystic tuberculosis of bone (Jungling's disease): report of a case. J Bone Joint Surg [Br] 1953; 35-B:285-7.

Goldblatt M, Cremin BJ. Osteo-articular tuberculosis: its presentation in coloured races. Clin Radiol 1978; 29:669-77.

Hartofilakidis-Garofalidis G. Cystic tuberculosis of the patella: report of 3 cases. J Bone Joint Surg [Am] 1969:51-A:582-5.

Komins C. Multiple cystic tuberculosis: a review and a revised nomenclature. Br J Radiol 1952; 25:1-8.

Kumar K, Saxena MB. Multifocal osteoarticular tuberculosis. Int Orthop $1988 ; 12: 135-8$.

Nielsen FF, Helmig O, de Carvalho A. Tuberculosis of calcaneus and talus with negative tuberculin skin test. Skeletal Radiol 1989; 18:1535.

O'Connor BT, Steel WM, Sanders R. Disseminated bone tuberculosis. J Bone Joint Surg (Am] 1970; 52-A:537-42.

Poppel MH, Lawrence LR, Jacobson HG, Stein J. Skeletal tuberculosis: a roentgenographic survey with reconsideration of diagnostic criteria. Am J Roentgenol 1953; 70:936-63.

Shannon FB, Moore M, Houkom JA, Waecker NJ. Multifocal cystic tuberculosis of bone: report of a case. J Bone Joint Surg (Am] 1990; 72-A:1089-92

Versveld GA, Solomon A. A diagnostic approach to tuberculosis of bones and joints. J Bone Joint Surg /Br] 1982; 64-B:446-9.

Westman JA, Barson WJ, Powell DA. Dactylitis and tuberculoid eruptions in a child with primary tuberculosis. Pediatr Infect Dis 1984; 3:251-3. 